\section{Size of In Vitro Plantlets Affects Subsequent Tuber Production of Acclimated Calla Lily}

\author{
Junne-Jih Chen ${ }^{1}$, Ming-Chung Liu, and Yang-Hsiu Ho \\ Technique Department, Taiwan Seed Improvement and Propagation Station, \\ Council of Agriculture, Hsinshe, Taichung, Taiwan 426, Republic of China
}

Additional index words. Araceae, Zantedeschia sp., tuber size, micropropagation

\begin{abstract}
Tuber production of calla lily (Zantedeschia elliottiana Spreng cv. Super Gold) was investigated using three size ranges $(7-10,4-7$, and $<4 \mathrm{~mm}$ shoot diameter) of in vitro plantlets acclimated in either pots or soil beds in a protected house. The shoots and tubers of large plantlets exhibited higher rates of dry-matter accumulation than did those of small plantlets. The diameter of tubers harvested from pots ranged from 0.67 to $4.1 \mathrm{~cm}$ with median values of $2.7,2.1$, and $1.9 \mathrm{~cm}$ for the plants derived from large, medium, and small plantlets, respectively. Plants grown in soil beds, regardless of size, produced larger tubers than did those grown in pots. Tubers $>3 \mathrm{~cm}$ in diameter developed on $25 \%$ and $52 \%$ of plants grown in pots and soil beds, respectively. Our results suggest that improved calla lily production could be realized by using larger in vitro plantlets as the source material and growing them in soil beds in a protected house.
\end{abstract}

Calla lilies and their hybrids are commercially available as cut flowers and potted plants (Corr, 1993; Letty, 1973). Growth habits of calla lily have been studied extensively (Corr and Widmer, 1991; Plummer et al., 1990), with major efforts focused on flowering control and tuber storage (Corr and Widmer, 1987, 1988). Growth regulator treatments have been evaluated with particular emphasis on increasing the number of flowers rather than on increasing the proportion of flowering-sized tubers (Funnell et al., 1988; Tjia, 1987).

Tuber size is one of the major flowering determinants in calla lily. Tubers $>3 \mathrm{~cm}$ in diameter are graded as flowering-sized, although small tubers can also flower after treatment with gibberellic acid (Corr, 1993; Dennis et al., 1994). From the growers' viewpoint, an ideal system for tuber production of calla lily should stress large tuber size and minimal loss due to infection by Erwinia carotovora ssp. carotovora or Erwinia chrysanthemi (Welsh and Clemens, 1992). Flowering-sized tubers of calla lily can be produced from either seeds or small tubers. Commercially, annual multiplication of calla lily through offsets and tuber division is practiced to increase the number of tubers of flowering size (Welsh and Clemens, 1992). However, this system is subject to the spread of cucumber mosaic cucumovirus (CMV) and dasheen mosaic potyvirus (DsMV) (Zettler and Hartman, 1987). In addition, division of field-grown

Received for publication 8 Mar. 1999. Accepted for publication 1 Sept. 1999. This work was supported by the National Science Council, Republic of China, under grant NSC882313B053001. The cost of publishing this paper was defrayed in part by the payment of page charges. Under postal regulations, this paper therefore must be hereby marked advertisement solely to indicate this fact.

1E-mail: tssgaga@ tubers are subject to infection by Erwinia soft rot, which causes serious losses.

Tissue culture is now used to increase new cultivars and provide clean materials free of known viruses (Cohen, 1981; Yao et. al., 1995). Tissue culture-derived plantlets have been proposed as an alternative planting material for tuber production in calla lily (Clemens and Welsh, 1993; Cohen, 1981). Although in vitro micropropagation methods for calla lily have been described (Cohen, 1981), little information is available on tuber production using tissue culture-derived plantlets. This study was designed to examine whether the quality of such plantlets could influence subsequent tuber growth and size distribution.

\section{Materials and Methods}

The experiment was conducted at the Taiwan Seed Improvement and Propagation Station from Oct. 1997 to Apr. 1998. Tissue culture-derived plantlets of calla lily, cv. Super Gold, were used as planting materials. In vitro plantlets were produced from stock tubers free of CMV and DsMV. Tubers were surface-disinfected with $0.5 \%$ sodium hypochlorite solution for $15 \mathrm{~min}$ followed by four rinses in sterile distilled water. Buds excised from the tubers were cultured on multiplication medium containing MS basic salts (Murashige and Skoog, 1962) supplemented with $3 \%$ sucrose, $0.054 \mu \mathrm{M} \alpha$-naphthaleneacetic acid (NAA), $9.29 \mu \mathrm{m}$ kinetin, and 2.22 $\mu \mathrm{M}$ benzyladenine (BA), and solidified with $0.8 \%$ agar (Sigma, St. Louis). The $\mathrm{pH}$ was adjusted to 5.7 before autoclaving. Cultures were incubated under a 16 -h photoperiod $(50$ $\mu \mathrm{mol} \cdot \mathrm{m}^{-2} \cdot \mathrm{s}^{-1}$ ) with a temperature of $25 \pm 2{ }^{\circ} \mathrm{C}$. Adventitious buds were taken through $8-10$ subcultures at 4-week intervals. When sufficient shoots was available, single shoots were transferred to rooting medium containing MS basic salts supplemented with $3 \%$ sucrose and $0.46 \mu \mathrm{m}$ kinetin, and solidified with $0.8 \%$ agar. These cultures were first incubated at $25 \pm 2{ }^{\circ} \mathrm{C}$ with a 16 -h photoperiod $\left(100 \mu \mathrm{mol} \cdot \mathrm{m}^{-2} \cdot \mathrm{s}^{-1}\right)$ for 2 weeks, and then placed on adjacent benches in a plastic-covered greenhouse (mean maximum light intensity $1050 \mu \mathrm{mol} \cdot \mathrm{m}^{-2} \cdot \mathrm{s}^{-1}$; mean temperature $22{ }^{\circ} \mathrm{C}$ ) for another 2 weeks of preacclimation. Preacclimated plantlets were rinsed in water to remove any medium, and misted with water to prevent wilting. Rooted plantlets were graded into three size groups (large, medium, and small) by shoot diameter and then transplanted in pots or in soil beds. The ranges of diameters of the basal part of the shoot for large, medium, and small plantlets were 7-10, 4-7, and $<4 \mathrm{~mm}$, respectively. For growth analysis, 600 plantlets of each size were planted in $11-\mathrm{cm}(0.52-\mathrm{L})$ pots with a growing medium of 5 sphagnum peat : 1 perlite (by volume). A randomized completeblock design was used with three replicates of each plantlet size. For comparing the difference in size distribution of tubers grown in pots and in soil beds, 120 plantlets of each size were first planted in pots for 4 weeks, then transferred to sandy soil beds at a density of 10 plants $/ \mathrm{m}^{2}$. A randomized complete-block design was used with three replicates of 40 plants each per plot. All plants were grown in an nonshaded greenhouse under natural sunlight (mean maximum light intensity during the experiment was $1950 \mu \mathrm{mol} \mathrm{m}^{-2} \cdot \mathrm{s}^{-1}$, relative humidity $70 \%$ to $80 \%$, and mean maximum and minimum temperatures $\approx 25^{\circ} \mathrm{C} / 16^{\circ} \mathrm{C}$ ). The plants were watered by drip irrigation system once a day at $0900 \mathrm{HR}$. Liquid fertilizer containing $200 \mathrm{mg} \cdot \mathrm{L}^{-1} \mathrm{~N}$ (Peter's $20 \mathrm{~N}-20 \mathrm{P}-$ 20K; Scotts-Sierra Horticultural Products, Maryville, Ohio) was applied through drip irrigation with an average $100 \mathrm{~mL} /$ plant every $10 \mathrm{~d}$. No additional fertilizers were applied during the experiment.

Twenty-four plants grown in pots were sampled randomly from each size treatment at 7 -d intervals for 24 weeks. Leaf numbers and areas were determined immediately after sampling. For shoot and tuber dry-weight determination, samples were oven-dried at $80^{\circ} \mathrm{C}$ for 2 d. Tubers were harvested 24 weeks after planting. The freshly harvested tubers were placed on benches in a shaded net house for 1 week to air-dry. The air-dried and cured tubers were graded according to the smallest diameter across the top of the tuber.

Data were analyzed by analysis of variance, and means were separated by the least significant differences (LSD) test. Linear regression was also used to characterize growth response over sampling stage for plants and tubers.

\section{Results}

Growth in pots. In the pot culture system, leaf area (LA) of all plants increased slowly during the first 6 weeks after planting (Fig. 1A). Thereafter, the LA increased linearly to a maximum $\approx 11-14$ weeks after planting. The rate of increase in LA was considerably higher in plants derived from large and medium plantlets, whereas the time of reaching maximum 
LA appeared to be independent of size. The mean maximum LAs attained by large, medium, and small plantlets were 81, 73, and 55 $\mathrm{cm}^{2}$ per plant, respectively (Fig. 1A). The LA started to decrease after 14 weeks of cultivation when leaves began to senesce. The decrease in LA was presumably due to the onset of leaf abscission, as indicated by the decrease in leaf number per plant (Fig. 1B). The pattern of change in leaf number during the culture period resembled that of change in leaf area (Fig. 1B). Leaf number increased rapidly during the first 11 weeks and reached a plateau $\approx 11-14$ weeks after planting. The maximum leaf numbers attained by plants derived from large, medium, and small plantlets were 8.1, 7.2 , and 7.6 per plant, respectively, at 14 weeks after planting. The change in leaf number after week 11 was similar for all treatments.

Dry-matter accumulation of shoots, regardless of plantlet size, changed little during the first 3 weeks of culture (Fig. 2A). Thereafter, it increased to a maximum at 14 weeks after planting, with a growth rate ranging from 27 to $40 \mathrm{mg} \cdot$ week $^{-1}$ per shoot (Table 1 ).

Tuber dry weight began to increase when LAs approached the maximum and continued to increase linearly until harvest (Fig. 2B). Tuber growth occurred only after leaf area had reached its maximum when small tubers were used for propagation (Clemens and Welsh, 1993). This was also the case in the present study with in vitro plantlets. Clemens and Welsh (1993) reported that the initiation and subsequent rate of tuber growth was primarily related to the availability of assimilates in excess of the demands of shoot development. This tendency is probably due to limitation of assimilate supply during the early stage of growth (Koble and Stephan-Beckmann, 1997). Our data showed little change in tuber dry weight until the shoots attained $75 \%$ to $80 \%$ of their maximum weight (Fig. 2A). Tuber growth rate (TGR), estimated by linear regression between 11 and 20 weeks after planting, ranged from 81 to $168 \mathrm{mg} /$ tuber per week (Table 1 ). The rate and duration of tuber growth was positively related to the original size of mother plantlets (Fig. 2B). About $95 \%$ of the final dry weight was accumulated by week 24,22 , and 20 for plants derived from large, medium, and small plantlets, respectively.

The difference in rate of tuber dry-matter accumulation was reflected in the size of tubers (Fig. 3A). For plants grown in pots, tuber size ranged from 0.7 to $4.1 \mathrm{~cm}$ in diameter, with median values of $2.7,2.1$, and $1.9 \mathrm{~cm}$ in diameter for the plants derived from large, medium, and small plantlets, respectively (Fig. $3 \mathrm{~A})$. For the small plantlets, $79 \%$ of the tubers were $<2.5 \mathrm{~cm}$ and only $0.4 \%$ were $>3 \mathrm{~cm}$ in diameter, whereas all tubers produced from large plantlets were $>2 \mathrm{~cm}$, and $\approx 25 \%$ were $>3$ $\mathrm{cm}$ in diameter (Fig. 3A).

Growth in soil beds. Tubers grown in soil beds showed a size trend similar to that of grown in pots. However, the pattern of tuber size distribution differed significantly from that of tubers grown in pots (Fig. 3B). Tuber size in soil beds ranged from 0.9 to $4.3 \mathrm{~cm}$ in diameter, with median values of $3.3,2.8$, and

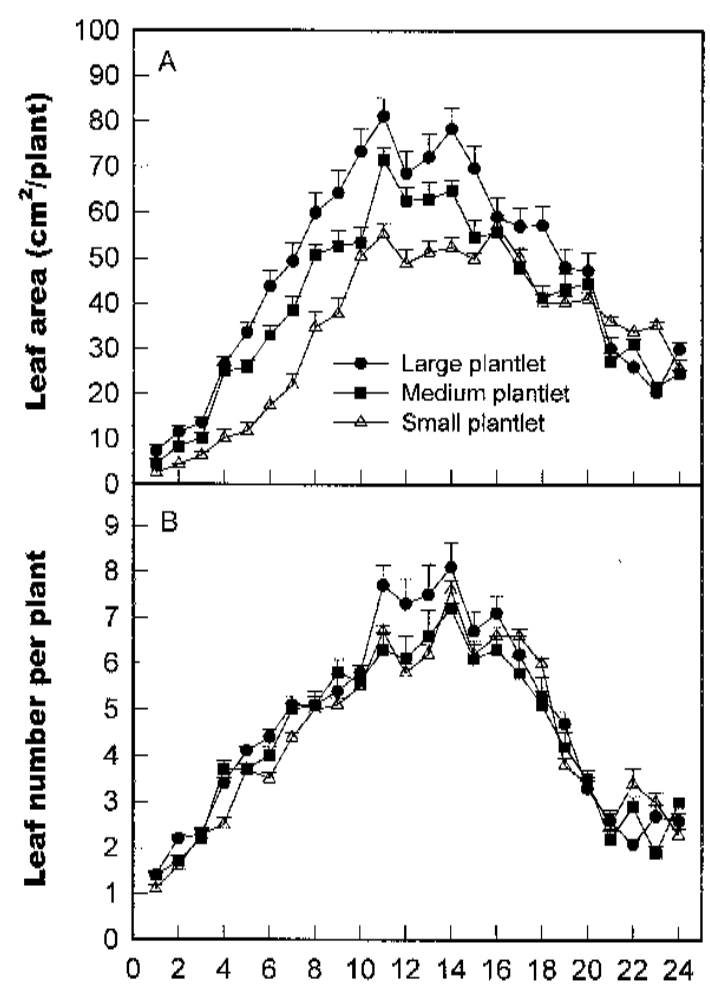

Weeks after planting

Fig. 1. (A) Leaf area and (B) leaf number of calla lily during plant development. The plants originated from large $(\bullet)$, medium $(\square)$, or small $(\Delta)$ tissue-culture-derived plantlets. Each point is the mean for 24 plants. Vertical bars denote \pm SE.

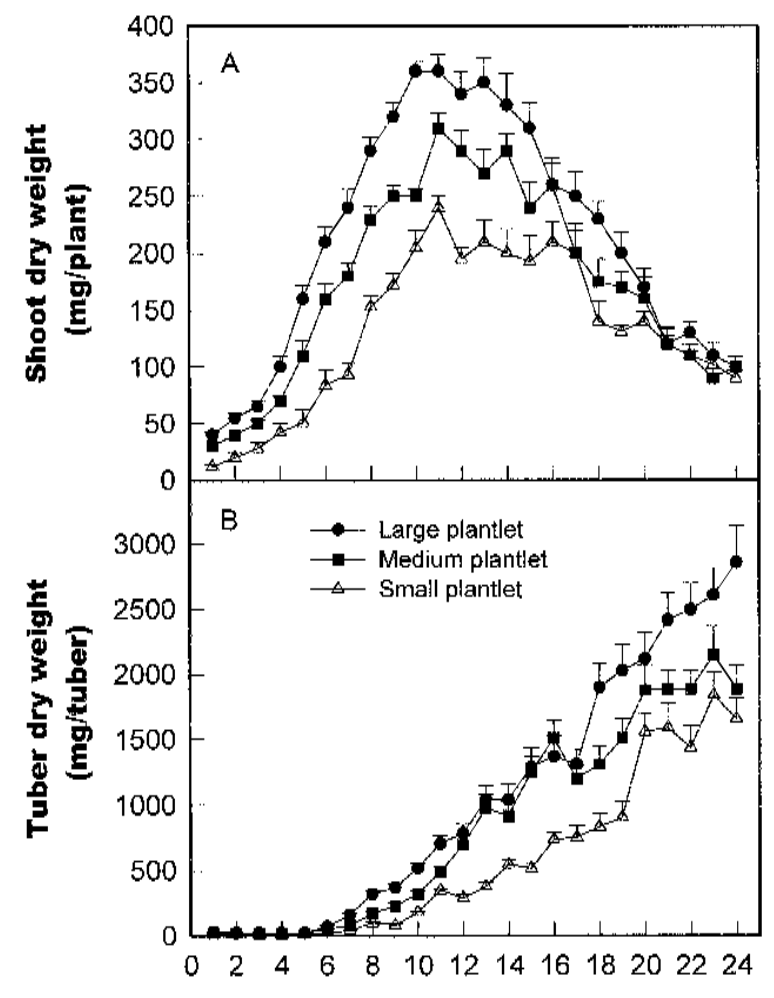

Weeks after planting

Fig. 2. Dry-matter accumulation in (A) shoot and (B) tuber of calla lily during plant development. The plants originated from large $(\boldsymbol{O})$, medium $(\boldsymbol{\square})$, or small $(\Delta)$ tissue-culture-derived plantlets. Each point is the mean for 24 plants. Vertical bars denote \pm sE. 
Table 1. Shoot and tuber growth rate of Zantedeschia produced from in vitro plantlets of three sizes.

\begin{tabular}{lcc}
\hline \hline $\begin{array}{l}\text { Size of } \\
\text { plantlets }\end{array}$ & $\begin{array}{c}\text { Shoot } \\
\text { growth rate }^{\mathrm{y}} \\
\left(\mathrm{mg}^{\mathrm{y}} \mathrm{week}^{-1}\right)\end{array}$ & $\begin{array}{c}\text { Tuber } \\
\text { growth rate }^{\mathrm{x}} \\
\left(\mathrm{mg.week}^{-1}\right)\end{array}$ \\
\hline Large & 40 & 168 \\
Medium & 33 & 132 \\
Small & 27 & 81 \\
LSD $_{0.05}{ }^{\mathrm{w}}$ & 4 & 19 \\
\hline
\end{tabular}

${ }^{\mathrm{z}}$ Size of plantlets was graded by measuring diameter at basal part of shoot. The shoot diameter for the large, medium, and small plantlets was 7-10 mm, 4$7 \mathrm{~mm}$, and $<4 \mathrm{~mm}$, respectively.

${ }^{y}$ Shoot growth rate was estimated by fitting a linear regression to the data for dry weight between 3 and 11 weeks after planting.

${ }^{x}$ Tuber growth rate was estimated by fitting a linear regression to the data for dry weight between 11 and 20 weeks after planting.

${ }^{\text {w } M e a n ~ s e p a r a t i o n ~ w i t h i n ~ c o l u m n s ~ b y ~ L S D, ~} P \leq 0.05$.

$2.5 \mathrm{~cm}$ for the plants derived from large, medium, and small plantlets, respectively (Fig. 3B). Plants grown in soil beds, regardless of plantlet size, tended to produce larger tubers than did those grown in pots. For the large plantlets, especially, the proportion of tubers that produced flowers was $25 \%$ in pots vs. $52 \%$ in soil.

\section{Discussion}

For calla lily growers, production requires a high proportion of flowering tubers (Corr and Widmer, 1988; Welsh and Clemens, 1992), and production of plantlets in vitro has become an alternative method (Cohen, 1981). Generally, tissue culture plantlets require two growing cycles ex vitro for tubers to reach sufficient diameters $(3-6 \mathrm{~cm})$ for flowering. Welsh and Clemens (1992) reported that micropropagated plants produced small tubers in their first growing season and reached flowering size in their second season. In the present study, however, we found that the variation of tuber size distribution depended on both the size of mother plantlets and the culture method. About half of the tubers produced by the larger in vitro plantlets grown in soil beds reached flowering size in only one growth cycle, whereas only $0.4 \%$ of tubers produced from small plantlets grown in pots reached flowering size within one season (Fig. 3).

The variation in size of in vitro plantlets is typical, and growers do not select for size for tuber production. Many researchers have suggested that the multiplication rates in vitro can be controlled by adjusting the form and/or concentration of plant growth regulators in the medium (Pierik, 1991). However, the conditions that favor adventitious bud formation (i.e., high multiplication rate) would usually limit plantlet development (i.e., plantlet size) during in vitro culture. Therefore, balancing the rate of multiplication and the size of plantlets in a tissue culture system is important for establishing a highly efficient system of tuber production that uses in vitro plantlets as mother stock.

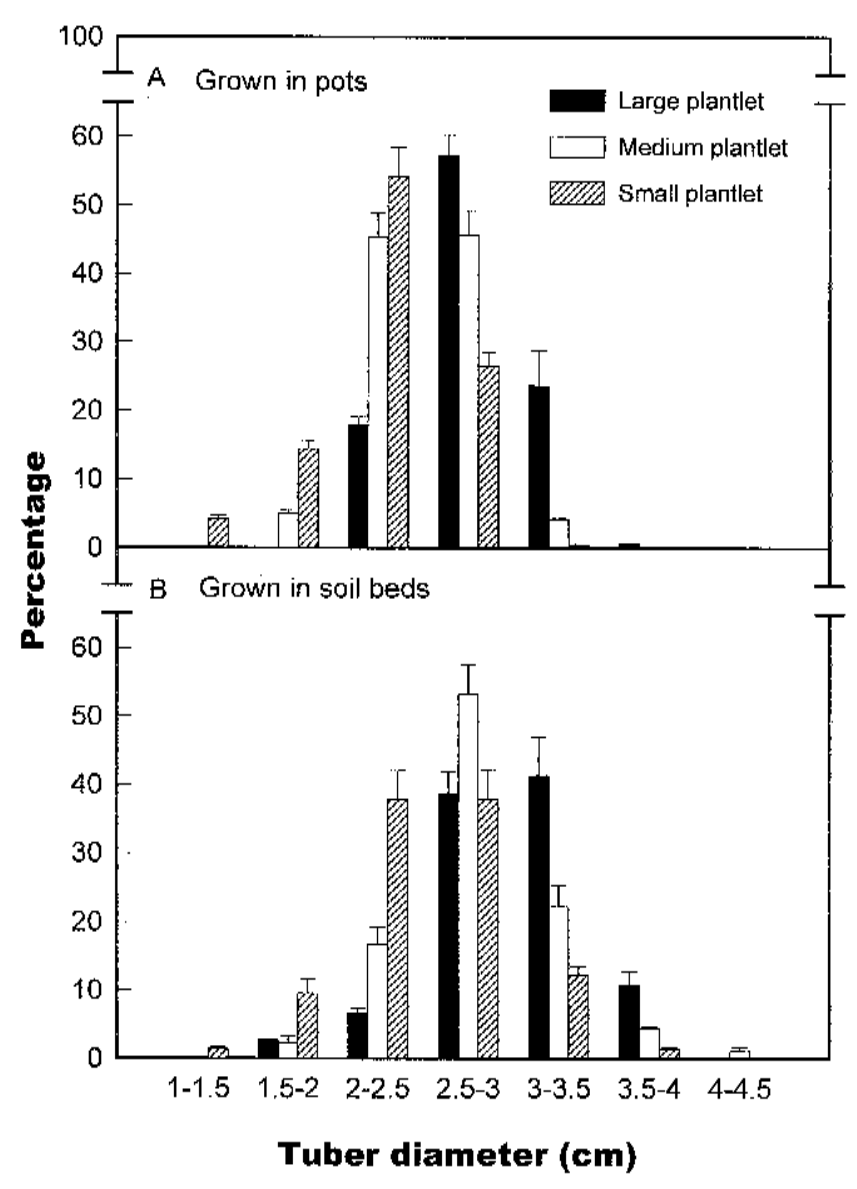

Fig. 3. Size distribution of calla lily tubers grown in (A) pots and in (B) soil beds under a protected house. Data were taken 24 weeks after planting. Vertical bars denote \pm sE.

\section{Literature Cited}

Clemens, J. and T.E. Welsh 1993. An overview of the New Zealand calla industry, research directions and year-round tuber production. Acta Hort. 337:161-166.

Cohen, D. 1981. Micropropagation of Zantedeschia hybrids. Comb. Proc. Intl. Plant Prop. Soc. 31:312-316.

Corr, B.E. 1993. Zantedeschia research in the United States: Past, present and future. Acta Hort. 337:177-189.

Corr, B.E. and R.E. Widmer 1987. Gibberellic acid increases flower number in Zantedeschia elliottiana and Z. rehmannii. HortScience 22:605-607

Corr, B.E. and R.E. Widmer 1988. Rhizome storage increases growth of Zantedeschia elliottiana and Z. rehmannii. HortScience 23:1001-1002.

Corr, B.E. and R.E. Widmer 1991. Paclobutrazol, gibberellic acid and rhizome size affect growth and flowering of Zantedeschia. HortScience 26:133-135.

Dennis, D.J., J. Doreen, and T. Ohteki. 1994. Effect of gibberellic acid 'quick-dip' and storage on the yield and quality of blooms from hybrid Zantedeschia tubers. Scientia Hort. 57:133-142.

Funnell, K.A., B.O. Tjia, C.J. Stanley, D. Cohen, and J.R. Sedcole. 1988. Effect of storage temperature, duration and gibberellic acid on the flowering of Zantedeschia elliottiana and Z. 'Pink Satin'. J. Amer. Soc. Hort. Sci. 113:860863.
Koble, H. and S. Stephan-Beckmann. 1997. Development, growth and chemical composition of the potato crop (Solanum tuberosum L.). II. Tuber and whole plant. Potato Res. 40:135-153.

Letty, C. 1973. The genus Zantedeschia. Bothalia 11:5-26.

Murashige, T. and F. Skoog. 1962. A revised medium for rapid growth and bioassays with tobacco tissue cultures. Physiol. Plant. 15:473497.

Pierik, R.L.M. 1991. Commercial aspects of micropropagation, p. 141-153. In: J. Prakash and R.L.M. Pierik (eds.). Horticulture. New technologies and applications. Kluwer Acad., Dordrecht, The Netherlands.

Plummer, J.A., T.E. Welsh, and A.M. Armitage. 1990. Stages of flower development and post production longevity of potted Zantedeschia aethiopica 'Childsiana'. HortScience 25:675676.

Tjia, B. 1987. Growth regulator effect on growth and flowering of Zantedeschia rehmannii hybrids. HortScience 22:507-508.

Welsh, T.E. and J. Clemens. 1992. Protected cropping of Zantedeschia tubers and cutflowers in New Zealand. Acta Hort. 319:335-340.

Yao, J.L., D. Cohen, and R.E. Roeland. 1995. Interspecific albino and variegated hybrids in the genus Zantedeschia. Plant Sci. 109:199-216.

Zettler, F.W. and R.D. Hartman. 1987. Dasheen mosaic virus as a pathogen of cultivated aroids and control of the virus by tissue culture. Plant Dis. 71:958-963. 